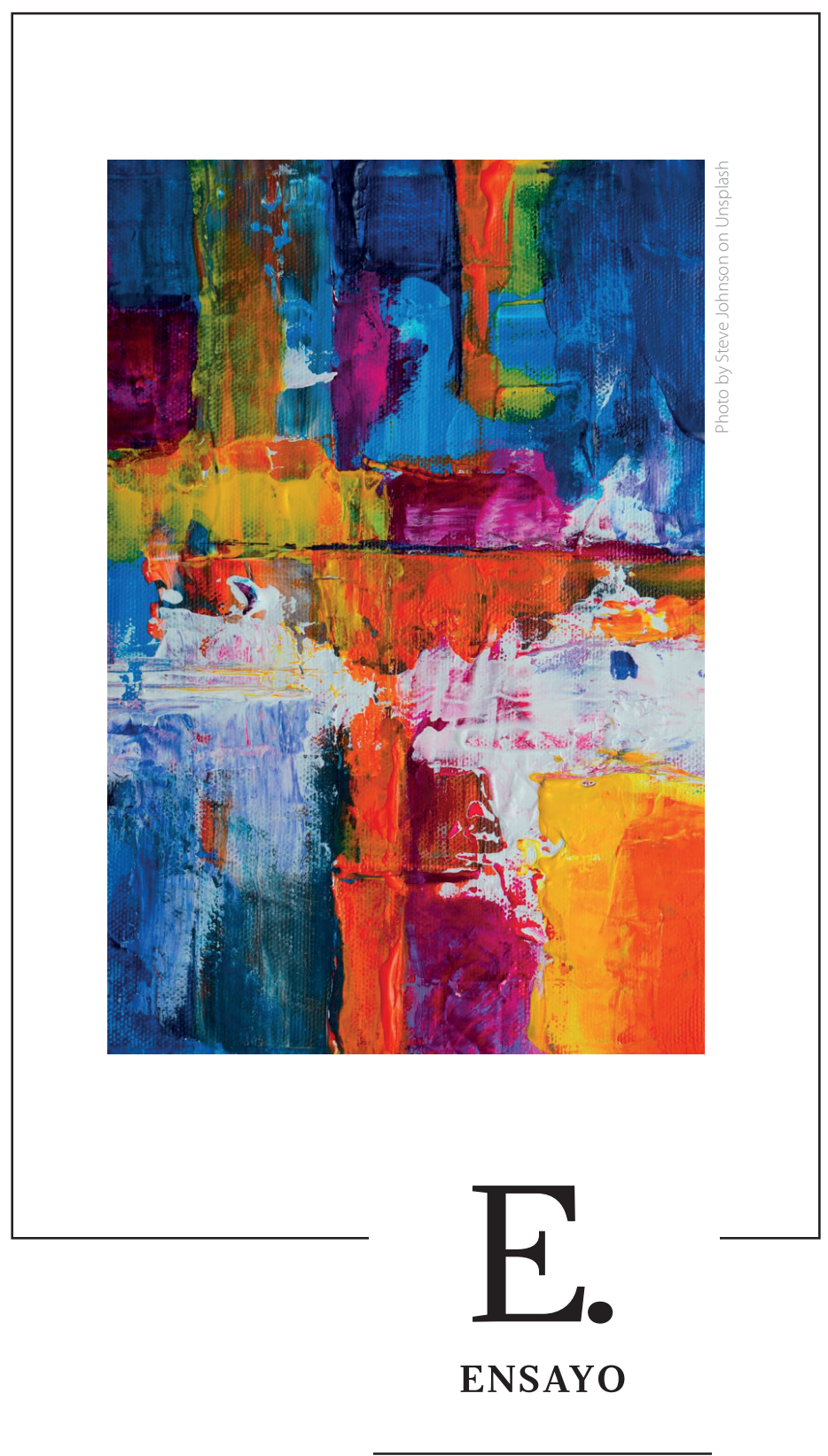




\title{
Presencia, identidad y afectividad en "Los heraldos negros", de César Vallejo. Apuntes de hermenéutica semiótica
}

\author{
Óscar Quezada Macchiavello
}

\section{INSTANCIA DE DISCURSO}

Hay dos razones, o quizá indisposiciones, que me han provocado siempre cierta reticencia a emprender el análisis o aún el mero comentario de la obra de un poeta. La primera concierne a la objetiva dificultad que entraña involucrarse, adentrarse, compenetrarse, bucear en el caudal simbólico del texto poético. Este, por la complejidad del entramado de sus niveles y de sus figuras de composición (y de descomposición), es el que con más fuerza pone a prueba la consistencia de una elaboración teórica y la coherencia de sus respectivos procedimientos metodológicos.

La segunda concierne a la ingenua concepción instrumental del lenguaje como algo exterior a los actores individuales o sociales que, lamentablemente, predomina en la crítica literaria habitual. Frente a ella, la metodología semiótica entiende un fenómeno de lenguaje como acontecimiento que constituye al ser humano haciéndolo carne-cuerpo-sujeto de comunicación. Dicho en breve, si biológicamente somos de ADN, semióticamente somos de lenguaje. Y existir es hacer discurso de ese ser lenguaje. Así pues, cualquier discurso entraña en su entraña un proceso de significación asumido por una enunciación.

En consecuencia, la instancia de discurso, más aún si es empíricamente identificada con un poeta, no es un autómata que ejerce una mera capacidad codificadora sino una presencia humana, un cuerpo sensible que se expresa. El corte epistemológico de la semiótica se da, pues, en lo que la teoría funcionalista llama mensaje. Se entiende no solo que en un discurso hay tantos "mensajes" como operaciones que lo constituyen, no solo que los códigos son competencias de quienes se comunican, sino también que, precisamente porque son humanos, los sujetos modelados por la teoría son de lenguaje. Yendo al objeto aquí atendido, la significación de un poema es inmanente. No radica en el autor sino en la estructura de la obra. Es ella la que da valor al autor y no viceversa.

No es necesario, entonces, conocer al autor para captar el sentido de la obra. Cualquier cosa que el poeta diga sobre su poema, ya no es su poema, ya es "otro discurso". 
Blanco cita a Eco, quien resume de modo brutal esa tesis: “El autor debería desaparecer después de haber escrito su obra. Para allanarle el camino al texto" (Eco, 1985, p. 14, citado en Blanco, 2009, p. 55) ${ }^{1}$. La vida contada es, eo ipso, una vida construida, radicalmente distinta de la vida vivida. Otra vez, tajante, Desiderio Blanco (2009) afirma: quien escribe su vida "inventa" su vida (p. 57).

El enunciador poético es una entidad semántica construida por el poema (ergo, por el lenguaje puesto en acto, en discurso); solo existe en la medida en que profiere enunciados. Ningún enunciado se enuncia solo. Ante un enunciado como "Hay golpes en la vida tan fuertes... ¡Yo no sé!" es necesario postular una instancia que lo profiera, la cual no es el "yo" enunciado, que "no sabe", sino la del "yo" de la enunciación, que, sin decirse, "dice que no sabe". Insistimos, pues, en que el enunciado no se dice a sí mismo, exige una instancia que lo produzca. Esa es la instancia dual de enunciación: enunciador / enunciatario, la cual es identificada empíricamente por el par escritor/lector, lingüísticamente por las marcas "yo / tú", semióticamente por la instancia de discurso de la que forma parte $\mathrm{y}$, fenomenológicamente, dentro de esa instancia, por el cuerpo propio y su "carne", núcleo sensorio-motor de la experiencia enunciante.

Voy a aprovechar, pues, las circunstancias que juegan a mi favor: el equipamiento conceptual de la semiótica, el hecho de no haber conocido personalmente a don César Vallejo o, más bien, el hecho de que don César Vallejo no me haya comentado "lo que quiso decir" en Los heraldos negros (a partir de aquí: LHN, texto del poema en Vallejo, 1997, p. 143)2.

\section{TÍTULO Y EPÍGRAFE}

Este emblemático poema juega como carta de presentación, u obertura, de un poemario del mismo nombre. Consta de cuatro cuartetos más un verso final que repite el primero. Estrofas de versos alejandrinos, a excepción de la primera (en la que los dos primeros versos son alejandrinos; y los dos siguientes, endecasílabos). En las estrofas regulares riman los versos pares; los impares están sueltos. En la primera estrofa riman el primero y el cuarto. El poema no guarda la forma perfecta: apela a la rima parcial y en una estrofa se permite otro metro y una rima diferente ${ }^{3}$.

1 Poco antes, Blanco ha recordado a Lévi-Strauss, quien sostenía que "no iríamos muy lejos en el análisis de las obras de arte si nos atuviéramos a lo que sus autores han dicho o incluso a lo que han creído hacer" (Lévi-Strauss, 1976, p. 596, citado en Blanco, 2009, p. 55).

2 "Luis Cernuda, exiliado en México, participaba en un recital poético. Después de leer su poema, un oyente levantó la mano y le preguntó: 'Señor Cernuda, ¿podría decirnos qué quiere decir con el poema?'. ‘Con todo gusto', respondió Cernuda. Abrió la cuartilla y leyó de nuevo el poema. Y añadió: 'Eso es lo que quería decir'" (Blanco, 2009, p. 62).

3 Observaciones formales tomadas de Ricardo Silva Santisteban. Identifica una vertiente negra de Vallejo proveniente "de un romanticismo afincado todavía en la tradición castellana modernista que intenta escandalizar al lector" (Vallejo, 1997, p. 61). 
A propósito de 'heraldo', Corominas (1976, p. 137) identifica una genealogía de términos que remite al francés héraut y, antes, al fráncico. La palabra heriald, hipotética, no documentada en texto alguno ni en el lenguaje hablado es, no obstante, considerada de segura existencia. Significa 'funcionario del ejército'. Compuesto de heri 'ejército' y waldan 'ser poderoso'. Hacia 1495 había sido castellanizado en la forma faraute, que significaba 'intérprete', 'mensajero de guerra"4.

Roles, ambos, de linaje semiótico: el primero desde la posición enunciataria, descifrador, dador de sentido; el segundo desde la posición enunciadora, emisario de un poderoso. Delegados ambos: uno del Hado, el otro del Imperio; en la figura de los 'heraldos' se encuentran, en estados puros o de mezcla, temas de Hermes y de Marte. El heraldo, en cuanto actor 'intérprete', convoca una pléyade de adivinos, augures y profetas. El heraldo, en tanto actor mensajero, convoca a emperadores, a reyes, a magos, a generales. En 'heraldos' conviven, pues, 'lecturas' y 'conflagraciones' (valga el quiasmo: lecturas de conflagraciones / conflagraciones de lecturas). Hermes, en particular, es el mensajero divino. Los heraldos negros, avatares de Hermes, traen mensaje del destino. El enunciador poeta toma posición en ese "hacer presente que lleva al conocimiento en la medida en que es capaz de prestar oído a un mensaje" (Heidegger, 1987, p. 110). De ahí que "lo hermenéutico no quiere decir primeramente interpretar, sino que, antes aún, significa el traer mensaje y noticia" (Heidegger, 1987, p. 111). Si en el mundo griego los poetas son mensajeros de los dioses, en el mundo que aquí exploramos los dioses ya no están, los ángeles tampoco, y al poeta solo le queda prestar oído a los 'heraldos negros' y ser mensajero de lo único "a la mano": el sufrimiento y la muerte.

Como epígrafe del poemario, Vallejo usa un leitmotif tomado del Evangelio: Qui pótest cápere capiat, cuya traducción es: "El que tenga oídos que escuche”; o bien, "El que quiera entender, que entienda" ${ }^{\prime \prime}$. Algunas figuras del Evangelio son recurrentes en LHN; podríamos decir que se trata de un poderoso intertexto, desacralizado por cierto, pero cuya aura sacra, numinosa, insiste y persiste a lo largo de varios poemas. Por lo pronto, sabida la etimología de "Evangelio", LHN serían un "Disangelio". Y los heraldos negros estarían en las antípodas de los ángeles blancos.

4 Informa, además, que del castellano faraute, el término pasó al francés faraud 'farolero'. En cuanto 'mensajero de luz', a las connotaciones herméticas añadiría las luciferinas. Esa observación es importante para nutrir la interpretación del imaginario discursivo de "Los heraldos negros".

5 Tanto en el Antiguo como en el Nuevo Testamento la Revelación es sometida a ocultación mistérica. “Ya desde los tiempos del salterio, cuando se anuncia que se va a publicar lo que está oculto desde la creación (Salmos 78, 2), se abre la boca muy estrecha para ello en parábolas, para que, según se explica no sea que con sus oídos oigan y con su corazón entiendan (Isaías 6,9-10) todos aquellos que aún no pueden o deben conocer el misterio" (Pla, 2018, p. 92). El Mesías viene a hacer oír y a hacer entender en el supuesto de que, respecto al Misterio del Reino de Dios, "su entero ver y entender no depende solo de la agudeza del intelecto sino, ante todo, de la limpidez de la conciencia, para que esta reciba con sus aguas sosegadas el fruto de su semilla interior" (Pla, 2018, p. 92). 
Precisamente, si de los 'heraldos' el enunciador poeta predica que son 'negros', entonces hace presente con el contracolor de todo color, asociado a las tinieblas arcaicas (o escatológicas), la indiferencia originaria, primordial y fatal. Todo enunciatario deviene presencia presenciando heraldos que son oscuros y se acercan en la oscuridad.

Si bien podemos imaginar que los 'heraldos' son 'negros', fuerza poética inmediata; también podemos ser más realistas e imaginar que los 'heraldos' están vestidos de negro, tienen puesta ropa negra. En el vaivén de un ser naturalmente negros a un cultural estar de negro vestidos, brota una pertinente escena práctica: el luto. Más aún por la ubicua y potente presencia de la muerte en el poemario. Tomemos nota.

\begin{abstract}
Instalado bajo el mundo, lo negro expresa la pasividad absoluta, el estado de muerte consumado e invariante entre las dos noches blancas donde se operan, en sus costados, los pasajes de la noche al día y del día a la noche. El negro es pues color de duelo, no como el blanco, sino de una manera más abrumadora. El luto blanco tiene algo de mesiánico. Indica una ausencia destinada a colmarse, una vacancia provisional. Es el duelo de los reyes y los dioses que obligatoriamente han de renacer: el rey ha muerto, ¡viva el rey!, cuadra perfectamente a la corte de Francia, donde el duelo se llevaba de blanco. El luto negro es, podríamos decir, el duelo sin esperanza. Como un 'nada' sin posibilidades, como un 'nada' muerto después de la muerte del sol, como un silencio eterno, sin porvenir, sin la propia esperanza del porvenir, resuena interiormente el negro, escribe Kandinski. El duelo negro es la pérdida definitiva, la caída sin retorno en la nada: el Adán y la Eva del zoroastrismo, engañados por Ahrimán, se visten de negro cuando son expulsados del paraíso. Color de condenación, el negro se convierte también en el color de la renuncia a la vanidad de este mundo, de donde los abrigos negros constituyen una proclamación de fe en el cristianismo y en el islam: el manto negro de los mawlavi - los derviches giradores - representa la piedra tumbal. Cuando el iniciado se lo quita para emprender su danza giratoria-, aparece vestido con una ropa blanca que simboliza su renacimiento a lo divino, es decir, a la realidad verdadera: entretanto han sonado las trompetas del juicio. En Egipto, según Horapolo, una paloma negra es el hieroglifo de la mujer que quedaba viuda hasta su muerte. Esta paloma negra puede considerarse como el eros frustrado, la vida negada. Es sabida la fatalidad manifestada por el navío de velas negras desde la epopeya griega hasta la de Tristán. (Chavalier y Gheerbrandt, 2003, p. 747)
\end{abstract}

Esta extensa cita de Chevalier y Gheerbrant resume las estructuras figurativas, temáticas y pasionales, todas ellas potenciales, que Vallejo disemina en LHN, tomando posición del lado del luto negro, no del blanco, es decir de un duelo más abrumador, más total. De una pérdida definitiva, de una fatal condenación, de una caída sin retorno, de un vacío de esperanza, ante los que cualquier fe de renacimiento divino resulta ridícula. En suma, de un nihilismo lanzado al silencio eterno, sin porvenir, sumido en lo imposible de lo posible, en la nada absoluta e inapelable. En LHN resuena el 'negro' con todos esos valores agregados. No obstante, de él también emerge la ética de renuncia a la vanidad del mundo, caldo de cultivo para tomas de posición solidaria, semillas de comunismo.

Pues bien, ¿cómo se hace presente el poeta en su poema? ¿Cómo deviene presencia que presencia presencias? ¿Qué presencias presencia? ¿Cómo le afectan? ¿Cómo construye y deconstruye su identidad? Como primer poema, LHN concentrala tónica afectiva 
dominante en la integridad del poemario. Los 'golpes en la vida, tan fuertes', recurrentes, investidos por distintas configuraciones, son la presencia central, la cualidad sensible en la que la enunciación pone la mira intensa. Un sujeto pasional-cognitivo, 'yo', aparece como presencia próxima, captado por los 'golpes', sometido a ellos, los observa, los sufre. En cuanto cuerpo, ese sujeto es la superficie misma en la que los golpes han impactado. Catáfora al verso 8: amplificación a nosotros, esos 'golpes' equivalen a 'los heraldos negros que nos manda la Muerte', 'ella', no-persona en horizonte amenazante. La presencia de los 'golpes' se interpreta como aviso, advertencia o anuncio de aniquilación. Por lo tanto, 'la Muerte' ocupa, a su manera, por un lado, el horizonte de campo, en cuanto destinadora de los 'golpes-heraldos', cuyo destinatario es el sujeto pasional-cognitivo, carne de impresión que muda a la tercera persona en las figuras del 'rostro más fiero' y del 'lomo más fuerte'; por otro lado, la Muerte ocupa también el centro de campo, en cuanto presencia presente en los 'golpes-heraldos' que golpean y afectan al sujeto en posiciones sucesivas: yo, ellos, nosotros.

Postulamos la presencia de la relación [golpe / golpeado] como cualidad sensible central del discurso; esto es, como algo, que, por una parte, ocupa cierta posición relativa a la posición de lectura dando lugar a efectos espaciales de distancia y de duración; en concreto, a afectos abiertos a lo más cercano y a lo más reciente. Por otra parte, esa presencia de los 'golpes golpeando' es algo que afecta en lectura con intensidad tónica, fuerte; y de tempo acelerado (en cuanto intempestivos) o ralentizado (en tanto 'son pocos'). Así pues, la presencia es un valor trabajado, a la vez, por una valencia extensa (espacialidad/ temporalidad) referida a las veces numerables y por una valencia intensa (tonicidad/tempo) referida a los golpes medibles (Zilberberg, 2006, pp. 86-92).

\section{ESTROFA 1}

Una primera voz, presupuesta, desembraga: 'Hay golpes en la vida'. Cabe una observación, no tan al margen. Considerando que la ' $\mathrm{H}$ ' es muda en español, la pronunciación de 'Hay' convoca a '¡Ay!', interjección de lamento, exclamación de dolor, expresión de pesar, que coloca al enunciador como paciente en acto de los 'golpes'. Esa 'otra lectura' no programada gramaticalmente, emerge como evento en el uso mismo de la expresión y de su coherencia con lo relatado. Ahí está. Latente ${ }^{6}$.

La vida, espacio extensivo de las veces, muchas, débiles, valor de universo, deviene conteniente de los golpes, pocos, pero fuertes: valor de absoluto. El ejercicio de la vida,

6 Si seguimos la potencialidad de esa latencia sentimos que los golpes nos están golpeando mientras enunciamos su presencia. De esa interjección escondida, el poema desciende a la proposición declarativa comandada por la " $\mathrm{H}^{\prime}$ que convierte la interjección (límite intenso) en proposición declarativa (límite extenso) y normaliza así la lectura. 
articulado por repeticiones, encarnadas de preferencia en inveteradas costumbres y en rituales cotidianos de supervivencia, es interrumpido "de vez en cuando" por eventos que sobrevienen y lo alteran. Definidas como "casos en los que se producen hechos", las veces dan forma al espacio-vida como lo que "llega a" un grado débil, átono, inacentuado, del sobrevenir. Como lo que, al transcurrir en el tiempo y en el espacio, da lugar a la enumeración y a la serialidad. El correlato de la vez, débil, átona, es el golpe, fuerte, acentuado. Lo fuerte, que define los 'golpes en la vida', es realmente fuerte, afecta toda carne de referencia.

'Yo no sé!'. Embrague de 'golpes', [ellos], a [yo]. Enunciación que, de golpe, hace golpe del enunciado. Su referente interno son los 'golpes' y, a su vez, es golpe (acento, exclamación). Resuena un lugar común del territorio socrático: Sólo sé que nada sé. O máximas como: el que no sabe y sabe que no sabe, sabe más que el que no sabe y no sabe que no sabe.

La voz pasional, presupuesta, afirma: 'hay golpes en la vida'. La voz cognitiva, puesta, manifestada por la primera persona, golpeada por la ignorancia, afirma su no saber. El enunciador paciente constata algo fuerte en la existencia; al mismo tiempo, ya como enunciador agente, se desentiende de ese algo, simulando ser un observador externo, trascendente. Yo solo constato en mí mismo que asíes, no me pregunten por qué. Siento los golpes, no sé sus causas. Las dos voces del yo poético se unifican en el mismo drama, modalizado por padecer y no saber. Dos sujetos en uno (golpeado por los golpes y por la ignorancia acerca de su origen y sentido). Sabe que hay golpes, no por qué y menos aún con qué fin. Sabe porque los siente en su mi-carne y los hace ser en el enunciado 7 .

El discurso va a dar vueltas expansivas en torno a la condensación del enunciado inicial: 'Hay golpes en la vida, tan fuertes'. Va a abrir nuevos horizontes, a diversificarlos en sus configuraciones. Va a insuflar fuerza en ellos, a imprimir una dirección de ascendencia tensiva: no solo existen, además redoblan y amplifican su intensidad, la que culmina con la tónica presencia de 'la Muerte', de la que son aviso. Ese trajín expansivo, que recurre al vector fórico del redoblamiento, refuerza la consternación en la que sumen los 'golpes'. Así, en el segundo verso, opera la semejanza, vía comparación: 'como', aplicada a la figura 'del odio de Dios'. Esta deviene parangón, imagen-fuente de los golpes cuyo destinatario-blanco es el "yo pasional". Un contundente inter discurso potencial, divulgado en la semiosfera cristiana, dice que Dios es fortísimo, todopoderoso. Si a esa fuerza exponencial, superlativa, que puede todo, se añade la pasión 'del

7 “El dolor como una 'sin-respuesta' persistente, como impotencia manifiesta del sujeto para formular una solución de tal naturaleza que sea capaz de hacer 'desaparecer el problema', el dolor como derrota segura del sujeto frente a una adversidad que, según todo lo hace pensar, jamás logrará superar, el dolor como distensión entre la potencialización, la temporalización del problema, vivida como posiblemente indefinida, y la virtualización de toda solución; en pocas palabras, una rima semántica que amarra, que sella de esa manera la incapacidad del sujeto, del pobre (hombre) en este caso, y su relación problemática con la vida" (Zilberberg, 2006, p. 333). 
odio', acentuamos el mencionado redoblamiento por amplificación. Ese 'odio de Dios' remite al arquetipo del patriarca autoritario que impone su ley. El "yo" poético, contestatario, responde así a un soterrado e institucional "yo" religioso; parafraseando: "de Dios siento odio, no amor". Los 'golpes en la vida' iconizan ese sentimiento repulsivo. Los 'golpes' dados por el 'odio de Dios' dejan un marcaje en el mí-carne enunciante. Una divinidad iracunda, colérica, golpea, pega. El enunciador pone al enunciatario ante los 'golpes', los desembraga, los objetiva, desde aquí los hace ser-ahí.

Ese mismo "yo-aquí", en el tercer y cuarto versos, presenta lo que sucede ante los golpes, ante su presencia ahí, ante su realidad. Ese ante coloca a los golpes antes de ese proceso icónico que asimila la temática del sufrimiento al agua que se va empozando. Pero la isotopía /física/, exteroceptiva, va a ser desplazada por la isotopía /psíquica/, interoceptiva: el efecto de ese afecto, tematizado ya, recae en la figura conteniente del "alma", donde parece que 'la resaca de todo lo sufrido se empozara'. El residuo de lo vivido-sufrido queda estancado cual creciente charco en el "alma". Late el potente arquetipo [psique:agua], mediación, en la antropología cristiana, entre [cuerpo:tierra] y [espíritu:fuego].

Los 'golpes', huellas en la isotopía /psíquica/, rigen sobre los 'golpes', meros impactos en la isotopía /física/. Su sola presencia da lugar a la imagen de lo que no fluye, de lo turbio que se acumula, de lo que queda grabado, de lo que pesa, del pesar cual creciente huella impregnada en la cavidad del sí-mismo. Culmina el cuarto verso con un nuevo embrague, reiterado testimonio del sujeto cognitivo-pasional, puesto más aquí ‘¡Yo no sé!', cuya eficacia consiste en devaluar sus propios simulacros, recién enunciados, regidos por 'como si ante'.

\section{ESTROFA 2}

En el quinto verso, los 'golpes' adquieren explícitamente valor de absoluto: 'son pocos', valencia concentrada, 'pero son', valencia tónica... recaen en las figuras somáticas del sujeto del padecer: 'rostro más fiero', 'lomo más fuerte'. Aunque la carne es agresiva, tensa, resistente, resulta sajada, quedan en ella 'zanjas oscuras'. Remisión a las heridas, a los sombríos resentimientos, a los sentimientos indescifrables, a los presentimientos de fosa, de tumba. El enunciador de LHN pone la acción de los 'golpes' en el centro del enunciado, pero también en el corazón de la enunciación exclamativa. Los 'golpes' son divisores, las 'veces' multiplicadoras; tanto en lo que respecta al relato del poema como en lo que concierne a su puesta en discurso. El ritmo discursivo oscila entre el estilo intensivo dado por la fuerza y unicidad de cada golpe, y el estilo extensivo manifestado en ese progresivo 'empozarse de lo sufrido', en esa acumulación de 'zanjas oscuras'. “Como el 'golpe' es 'seco' y 'súbito', su medida indudable fija al mismo 
tiempo la de la 'vez' como extensión" (Zilberberg, 2006, p. 65). Formas imperativas "indican o recuerdan al usuario los matices que hay que respetar para conferir a la ejecución de los programas la prosodia que les conviene" (Zilberberg, 2006, p. 66). El enunciador, en cuanto usuario, entiende que los golpes dividen la vida, la cortan, la tasajean, la matan, pero a la vez se extienden en ella como huellas de las que el poema hace memoria.

Recién en el verso 7 la modalidad factitiva reinante, típica de la dimensión pragmática, da paso a la probabilidad: 'Serán talvez'. 'Serán' opera como anáfora a los 'golpes' que, esta vez, se invisten ora como 'los potros de bárbaros atilas', reforzando la apertura de 'zanjas oscuras'; ora, octavo verso, como 'los heraldos negros que nos manda la Muerte'. La forma 'talvez' hace que estas figuras se deslicen, como probabilidad, a la dimensión cognitiva del discurso, esto es, a algo que el enunciador cree, pero no confirma. (Como si se tratase de un "tambaleo" cognitivo frente a la fuerza afectiva de los golpes).

En el verso 8 aparece un embrague a [nosotros], actante cognitivo, destinatario-blanco de los mensajes cifrados transmitidos por esos 'heraldos negros', míticos avatares de Hermes, actantes de control, delegados de 'la Muerte', destinadora-fuente que nos los 'manda'. (Notar la doble acepción de este último verbo: /envía/ y /ordena/, esta última, marca de jerarquía, índice de autoridad). Un saber potencial de la praxis enunciativa se agazapa en esas figuras: "se sabe" que donde pisaban las huestes de Atila no volvía a crecer vida. Pero el poeta habla de 'atilas' con minúscula, acoplando los 'golpes' a la cantidad, a la epidemia, a la proliferación, a la plaga. Por lo demás, dice 'bárbaros', actantes que, en profundidad vertiginosa, vienen desde un horizonte hacia un centro ocupado por el enunciador mismo, colocado en el lugar imaginario del civilizado, del cristiano. Entonces, se trata siempre de lo extraño, de lo extranjero, de lo invasor, del enemigo. "Se sabe", además, que la sequía y la carencia de frutos convierten en nómade al hombre... la tierra que pisa está maldita.

Se confrontan dos formas de vida (una sufriente, debilitada; la otra mensajera de muerte, fortalecida), dos líneas de congruencia 'vertical' entre planos 'horizontales' de oposiciones: ["tierra fértil" vs "tierra estéril"; "verdor" vs "desierto"; "bendición" vs "maldición"; "sedentarismo cultivado" vs "nomadismo originario"; "ciudad" vs cábila; "seguridad" vs "errancia"]. El Occidente cristiano promueve la forma de vida del cultivo-ciudad, introduce el concepto de "cultura", de "orden", de "tiempo". Desde ahí el poema enuncia un mundo amenazado. El Asia Central, de donde provienen los 'bárbaros atilas', espacio exterior a la semiosfera presupuesta, es percibido desértico, regido por el nomadismo, por la precariedad e inestabilidad, con "órdenes" y "tiempos" de morfologías y sentidos distintos de los urbanos. 
Por lo demás, cabe reiterar la ausencia de color y de luz hecha presente en los 'heraldos negros'. Los 'golpes' absorben nuestra energía vital, la debilitan, convirtiéndola de viviente en muriente, tal como algo negro absorbe la luz y no la devuelve. Delegados de 'la Muerte', los 'heraldos' son oscuros y dejan oscuridad a su paso, predican con 'golpes'. Los vivos murientes de LHN se contraponen a los muertos vivientes del Evangelio.

\section{ESTROFA 3}

El verso 9 supone la modalización factitiva 'Son': se realiza lo regido por 'la Muerte'. Mediante la onomástica 'Cristos', el poeta engancha con el discurso evangélico. No hay un Cristo, que valdría como "él", objetivado, exterior, personaje de la historia sagrada. Más bien hay muchos y valen como actantes interiores, subjetivos, provenientes del alma, alojados en ella. Los 'golpes' son ahora las 'caídas hondas', de esos Cristos (anáfora a los 'pozos' de las 'resacas', a las 'zanjas oscuras', a las pisadas de los 'potros de bárbaros atilas'). Del alma-pozo, cavidad de todo lo sufrido, verso 4; al alma-morada de los Cristos (hondamente) caídos. Homología: el alma pozo es al alma morada lo que todo lo sufrido es a las caídas de "nuestros" Cristos. Se podría discutir, en una pertinencia gramatical, que el enunciado desembraga, objetiva, a "los" Cristos (no a "nuestros" Cristos). Replicaríamos que no los desembraga en una "historia sagrada" sino en "el alma" (del que habla). Y el que habla ha mencionado antes a "bárbaros atilas" (negándole la mayúscula al rey de los hunos). El "yo" poético toma posición en el destinatario cristiano, "nosotros" de la "historia sagrada", semiosfera occidental. Como vimos, los hunos, "ellos en sus potros", oscuros heraldos arrasadores, avasalladores, vienen desde los bordes, destruyendo "la" vida. "Potros" acerca "golpe" a "galope". A pisada en el "alma tierra", alma corporal, paciente extensa de su brutal trotar. En el mundo hay "atilas", en la hondura del alma, alma aire, hay 'Cristos' caídos. Esas 'hondas caídas' no solo dan profundidad al alma, también asimilan la vida humana a la pasión de Cristo, en particular, al vía crucis: los golpes devienen latigazos, bofetadas, caídas... que son solo la superficie figurativa, corporal, de las penas tematizadas en el 'alma' espiritual. Los 'atilas' dibujan la dimensión horizontal del dolor; las 'caídas', su dimensión vertical. Espacialización en cruz.

Verso 10: los 'Cristos del alma', sin perder presencia, dejan su lugar a 'alguna fe adorable que el Destino blasfema'. La praxis discursiva ha coagulado la constelación: fe, religión, Cristo, adoración. Generando coherencia: "Con los Cristos del alma cae también alguna fe adorable que el Destino blasfema...". Dos actantes entran a escena discursiva, aparecen por desembrague: la "fe adorable", "ella", tras la cual está el sujeto feligrés, devoto, ferviente creyente en una religión; y el Destino, "él", destinador-juez que, del lado de 'la Muerte', sanciona como disfórico el objeto adorado por aquel. Los 'golpes en la vida' coinciden con las blasfemias del Destino. La 'fe adorable' cae profanada por el 
insulto. 'Destino' y 'sentido' permutan su diferencia en el mismo universo. Los 'golpes' y todas sus figuras, del lado del Destino, siguen el sentido de un esquematismo ascendente que culminará en 'la Muerte'. El 'yo' poético, destinatario de los 'golpes', con sus Cristos, con su fe adorable, a partir de la acentuación de esos 'golpes', sigue el itinerario de un esquematismo descendente, su resistencia aminora hasta la honda extenuación.

Verso 11: "Esos golpes sangrientos son las crepitaciones de algún pan que en la puerta del horno se nos quema", imagen quizá prosaica pero muy intensa pues entraña embrague a ese 'nosotros' destinatario de los 'heraldos negros' cuyo destinador es 'la Muerte', quien se consume y consuma en el centro del campo de presencia: los 'golpes', ahora 'sangrientos', se contagian de carne torturada. 'Son', se realizan, en cuanto 'crepitaciones de algún pan', figuras de un fuego impactando la masa de harina. Así como los galopes de los potros lo son los de una carne animal que horada la carne de la tierra, ahora se trata del fuego que hace vibrar 'algún pan'. La semiosfera cristiana, iterativa, presiona la lectura: el 'pan' es el cuerpo de Cristo, el 'vino' su sangre, el 'fuego' bautiza en Espíritu, no quema. El fuego del horno quema, el del espíritu libera, transforma.

Hay 'golpes sangrientos' que son como las 'crepitaciones de algún pan'. Herida. Sangre. Carne quemada. Sacrificio inútil. La figura retórica del 'pan que se quema en la puerta del horno' es la de la 'fe adorable', la del plan, el programa, el proyecto, la ilusión, el sueño, listo para realizarse y que, por una u otra razón, no se lleva a cabo. El hombre se esfuerza, propone; 'el odio de Dios' dispone. El pan es la fe, pero también es el plan de vida en el que se han ido sudores, insomnios, desvelos, preocupaciones. El 'pan quemado', parangón del objeto desprovisto de valor alimenticio, remite a las decepciones y fracasos. Y 'quemado en la puerta del horno' significa que se nos malogró cuando no faltaba nada para bien lograrse ${ }^{8}$.'La resaca de todo lo sufrido' empozada en el alma, por anáfora a los versos 3 y 4 ; y lo vivido empozado como charco de culpa, en la mirada, por catáfora al verso 16; son efectos de la objetivación de los 'golpes', convocan ambos la figura del 'charco'. Las crepitaciones del pan que se quema en la puerta del horno, a su vez, convocan la figura del 'chasco'. 'Charco' es a resentimiento lo que 'chasco' es a frustración, a decepción. Circuito del pesar que deja sus huellas en [nosotros].

\section{ESTROFA 4}

Si bien en la perspectiva sintáctica confirmamos un desembrague de 'nos' a 'él', semánticamente ha quedado fijada, consolidada, una identidad: \{“yo" = "él" $\}$. Quien dice: 'Y

8 "La figura del disgusto sanciona negativamente el proceso vivido: 'estado de conciencia doloroso causado por la pérdida de un bien'. Ese bien perdido, y ahora 'lamentable', es la participación del enunciador en la doxa a través de la confianza y de la adhesión a la vida que la doxa propaga o exige, según los casos" (Zilberberg, 2006, p. 333). 
el hombre...jPobre...pobre!', encarna al "yo", poeta-hombre, que toma distancia de "él”, el hombre, y lo compadece modulando el adjetivo en exclamación ralentizada por los puntos suspensivos ${ }^{9}$. ¿Desde dónde se evidencia, en el verso 14, esta conmiseración del individuo 'último' por su propia especie así objetivada?: 'Vuelve los ojos, como cuando por sobre el hombro nos llama una palmada;'. [Él], pobre actor, vuelve los ojos, la mirada, al [yo] observador relator... el símil que sobreviene articula, por suma, la identidad ya señalada: \{“yo + él = nosotros”\}. 'Él' vuelve los ojos tal como lo hacemos 'nosotros', individuos de una pobre especie (receptores de los heraldos y del pan quemado, ambos negros). La figura, también prosaica, de la 'palmada sobre el hombro', atenúa sin duda la fuerza de 'los golpes', remite al abrazo de pésame o al gesto de consuelo... pero solo para que el enunciatario se dé cuenta de que 'él' ya está sobrepasado, alienado, excitado, excedido por 'ellos': 'vuelve los ojos locos'. 'Y todo lo vivido' (repercusión anafórica al tercer verso: 'todo lo sufrido'), 'se empoza' (ídem al cuarto verso). Lo sufrido es lo vivido. $Y$ 'se empoza, como charco de culpa, en la mirada'. El hombre ya no tiene recursos para desaguar la culpa empozada. Lo 'sufrido' que 'se empozara', de la primera estrofa, es, ahora, 'un charco de culpa'. Vimos ya que, entre ambos charcos, sobreviene el chasco. Lo sufrido, frustración de por medio, deviene culpa. El alma recipiente es, ahora, 'la mirada'. El alma de ese pobre ser se expresa en su mirada de ojos locos, revela la culpa atorada, atascada. La blasfemia del Destino es el veredicto del odio de Dios, de ese malvado juez que nos ha declarado ya desde siempre culpables. La locura, paroxística, se entrama con la culpa y, en horizonte, con la frustración. Evidencia (en la) videncia, mirada eternizada en un ahora fatal.

\section{CODA}

Poema de dominante 'objetiva', limita la construcción del efecto de 'intersubjetividad' al [tú] implícito, articulado bien sea desde el [yo] o bien desde el [nosotros], marcas que aparecen con seis embragues: tres a [nosotros] (versos 8, 12 y 14) y tres a [yo], semejante al apóstol Pedro, el enunciador niega tres veces saber algo (versos 1, 4, 17). Si bien no hay lugar para un [tú] explícitamente enunciado, sí lo hay para un [él] humano, demasiado humano (Nietzsche dixit). No obstante, los seis embragues mencionados crean y refuerzan la distancia con ese [él]. Sea como fuere, estén vestidas de [él] o de [nosotros], las figuras humanas ven modalmente menoscabado su poder al extremo de la impotencia; sacudidas por los poderosos 'golpes'. Estos, desplegados en una cadena de

9 La 'pobreza' en LHN, se siente disfórica. Mientras que en el lenguaje testamentario al par riqueza/pobreza corresponde el par posesión/privación de atributos. En Mateo 5, 3 Jesús dice: Bienaventurados los pobres de espíritu refiriéndose a aquellos que han alcanzado la conciencia pura del hombre espiritual. En el Salmo 49, 3, se llama ricos a los hijos de Adán (hombres psíquicos) y se llama pobres a los hijos de hombre (hombres espirituales). Tomado de Pla, 2018, p. 93. 
semejanzas, ocupan el centro del campo de discurso. A todo esto, el reino de las mayúsculas acoge cuatro pobladores: del lado tónico, 'Dios', 'Destino' y ‘Muerte'; del lado átono, los humanizados 'Cristos del alma' con sus 'hondas caídas'. Reveladora asimetría. Fin: repetición del primer verso. Más que clausurar un circuito, esa operación apunta a una apertura, a una repercusión interminable del acento afectivo puesto sobre el retumbar de los mortales 'golpes'.

\section{REFERENCIAS}

Blanco, D. (2009). Vigencia de la semiótica y otros ensayos. Lima: Universidad de Lima, Fondo Editorial.

Chevalier, J. y Gheerbrandt, A. (2003). Diccionario de los simbolos. Barcelona: Herder.

Eco, U. (1985): Apostillas a El nombre de la Rosa. Barcelona: Lumen.

Heidegger, M. (1987). De camino al habla. Barcelona: Ediciones del Serbal-Guitard.

Landowski, E. (1993). La sociedad figurada. Ensayos de sociosemiótica I. México, D. F.: Fondo de Cultura Económica.

Landowski, E. (2007): Presencias del otro. Ensayos de sociosemiótica II. Lima. Universidad de Lima, Fondo Editorial.

Lévi-Strauss, C. (1976): Mitológicas IV. El hombre desnudo. México, D. F.: Siglo XXI.

Pla, R. (2018). El hombre, templo del Dios vivo. Barcelona: Sirio.

Vallejo, C. (1997). Poesía Completa I. Lima: Pontificia Universidad Católica del Perú.

Zilberberg, C. (2006). Semiótica tensiva. Lima: Universidad de Lima, Fondo Editorial. 